\title{
Soil characterization using patterns of magnetic susceptibility versus effective radium concentration
}

\author{
F. Girault ${ }^{1}$, C. Poitou ${ }^{2}$, F. Perrier ${ }^{1}$, B. P. Koirala ${ }^{3}$, and M. Bhattarai ${ }^{3}$ \\ ${ }^{1}$ Équipe de Géomagnétisme, Institut de Physique du Globe de Paris, UMR7154, CNRS-Université Paris Diderot, \\ Sorbonne Paris Cité, 1 rue Jussieu, 75238 Paris cedex 05, France \\ ${ }^{2}$ Équipe de Paléomagnétisme, Institut de Physique du Globe de Paris, UMR7154, CNRS, 1 rue Jussieu, \\ 75238 Paris cedex 05, France \\ ${ }^{3}$ National Seismological Centre, Department of Mines and Geology, Lainchaur, Kathmandu, Nepal
}

Received: 24 March 2011 - Revised: 5 July 2011 - Accepted: 18 July 2011 - Published: 23 August 2011

\begin{abstract}
Low-field magnetic susceptibility $\chi_{\mathrm{m}}$ and effective radium concentration $\mathrm{EC}_{\mathrm{Ra}}$, obtained from radon emanation, have been measured in the laboratory with 129 soil samples from Nepal. Samples along horizontal profiles in slope debris or terrace scarps showed rather homogeneous values of both $\chi_{\mathrm{m}}$ and $\mathrm{EC}_{\mathrm{Ra}}$. One sample set, collected vertically on a lateritic terrace scarp, had homogeneous values of $\mathrm{EC}_{\mathrm{Ra}}$ while $\chi_{\mathrm{m}}$ increased by a factor of 1 to 10 for residual soils and topsoils. However, for a set of samples collected on three imbricated river terraces, values of $\mathrm{EC}_{\mathrm{Ra}}$, homogeneous over a given terrace, displayed a gradual increase from younger to older terraces. By contrast, $\chi_{\mathrm{m}}$ showed more homogeneous mean values over the three terraces, with a larger dispersion, however, for the younger one. Similarly, Kathmandu sediments exhibited a large increase in $\mathrm{EC}_{\mathrm{Ra}}$ from sand to clay layers, while $\chi_{\mathrm{m}}$ increased moderately. The combination of $\chi_{\mathrm{m}}$ and $\mathrm{EC}_{\mathrm{Ra}}$, thus, provides a novel tool to characterize quantitatively various soil groups and may be of interest to distinguish modes of alteration or deposition histories.
\end{abstract}

\section{Introduction}

The soil plays an important role in the evolution of the subsurface and the exchange of matter between the bedrock and the atmosphere and, as such, the understanding of its properties is a prerequisite in numerous fundamental problems and environmental applications (e.g. Musy and Soutter, 1991). Reconstructing the past history of deposition and erosion of

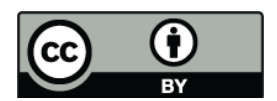

Correspondence to: F. Girault (girault@ipgp.fr) a given soil, for example, is useful for the reconstruction of past climates (e.g. Gu et al., 1997; Lagroix and Banerjee, 2002). To assess the history of a given soil or its ability to store, release or transmit pollutants, some knowledge of its physical and chemical properties is needed. Unfortunately, a soil is a complex multiphase time-dependent non-linear system, difficult to characterize and model (Musy and Soutter, 1991). While numerous empirical methods have been developed since the nineteenth century, it is difficult in practice to measure extensively all known soil parameters. Methods that are both easy to implement, as well as efficient and unambiguous, might therefore be of great help, in particular in a context of the planet's threatened soils (Banwart, 2011).

Methodological aspects of environmental magnetism, introduced in Thompson and Oldfield (1986), can provide valuable information about the history, nature, main distribution pathways (Evans and Heller, 2003), transformations and occurrence of ferromagnetic minerals in soils. For example, low-field magnetic susceptibility $\left(\chi_{\mathrm{m}}\right)$, one widely used magnetic property of minerals, has been proposed as a powerful tool to characterize a soil layer, both in the laboratory and in the field, in the context of atmospheric pollution in the vicinity of roads or industrial zones (e.g. D'Emilio et al., 2010). Indeed, magnetic susceptibility, essentially controlled by the concentration of magnetite, maghemite or greigite in natural conditions, is also increased in the presence of heavy metals such as iron, lead or mercury (e.g. Hanesch and Scholger, 2002; Karimi et al., 2011). The spatial variation of $\chi_{\mathrm{m}}$ may also provide some important information on the soil chemical evolution. For example, topsoils in temperate, Mediterranean, subtropical and tropical zones show higher values than subsoils (Le Borgne, 1955), an effect

Published by Copernicus Publications on behalf of the European Geosciences Union. 
referred to as magnetic enhancement of topsoils and originally considered to be due to bioreduction of iron in anaerobic conditions (Le Borgne, 1955; Mullins, 1977). Extensive data sets obtained recently, however, rather suggest a largely abiotic system where secondary ferrimagnetic mineral formation is essentially controlled by the weathering capacity to supply iron to the surface soils (Blundell et al., 2009). This data set also shows higher magnetic concentrations over specific parent material such as schists, slates, mudstones and limestones. This does not imply, though, that $\chi_{\mathrm{m}}$ can be easily used to characterize soil deposition and chemical evolution versus slope dynamics. Indeed, inconsistent values of magnetic enhancement suggest that the relationship between $\chi_{\mathrm{m}}$, parent material and transport is in general difficult to decipher (e.g. de Jong et al., 1998; Dearing et al., 1996). However, the spatial variation of $\chi_{\mathrm{m}}$, both laterally and with depth, remains impressive and the complex patterns of $\chi_{\mathrm{m}}$, whose measurement is simple, fast and cheap, nondestructive and possible both in the laboratory and in the field, could allow reliable interpretations if it can be combined with another physical parameter.

Effective radium concentration $\left(\mathrm{EC}_{\mathrm{Ra}}\right)$ refers to the radon gas source term (Stoulos et al., 2004), namely radium concentration $C_{\mathrm{Ra}}$ multiplied by the emanation factor $E$, which is the probability that radon, a decay product of radium, is produced in the pore space and can escape from the bedrock or soil to the atmosphere. This parameter $\mathrm{EC}_{\mathrm{Ra}}$ can be easily measured in the laboratory and, while spatial variations of radon concentration in the soil were observed long ago, the interpretation was not considered straightforward and systematic (Botset and Weaver, 1932). Nevertheless, $\mathrm{EC}_{\mathrm{Ra}}$ shows definite and reproducible spatial variations, with values varying over more than two orders of magnitude in regular conditions (Girault et al., 2011) and more in soils in uranium mining zones or affected by wastes of uranium industry (Sahoo et al., 2010). Radium is a member of the uranium decay chain, and, like other radionuclides which are not in radioactive equilibrium in a given sample, it can reveal the weathering history of a soil (Gu et al., 1997). Furthermore, it can be an interesting proxy to characterize the soil history and its ability to store and release pollutants. Indeed, while radium shows a preferential sorption onto ferric oxyhydroxides (Ames et al., 1983; Flexser et al., 1993) and thus might be well correlated with $\chi_{\mathrm{m}}$, it also shows an even stronger affinity for organic matter in clays (Greeman et al., 1999). The parameter $\mathrm{EC}_{\mathrm{Ra}}$ is complicated by the presence of the emanation factor, which depends mainly on grain size distribution, temperature or humidity (Markkanen and Arvela, 1992; Adler and Perrier, 2009; Breitner et al., 2010), but this dependence itself might be a powerful index to distinguish various soil types.

In this paper, we explore the potential of combining $\chi_{\mathrm{m}}$ with $\mathrm{EC}_{\mathrm{Ra}}$ to distinguish various soils which might not be sufficiently well characterized by one of these parameters only. For this purpose, we use various coherent sets of soil samples coming from sites located in the Himalayas of Nepal, which have been little affected by industrial activities.

\section{Methods}

The magnetic susceptibility $\kappa$ is defined as the ratio of the induced magnetization $M$ by the inducing magnetic field $H$ (Evans and Heller, 2003):

$\kappa=\frac{M}{H}$.

Both $M$ and $H$ are measured in $\mathrm{A} \mathrm{m}^{-1}$, therefore $\kappa$ is dimensionless. The low-field specific magnetic susceptibility $\chi_{\mathrm{m}}$, expressed in $\mathrm{m}^{3} \mathrm{~kg}^{-1}$, is defined as the ratio of $\kappa$ by the density of the sample. As an induced magnetization parameter, low-field magnetic susceptibility is a response of the contribution from all minerals present in the bulk sample, whether they are dia-, para-, or ferromagnetic. Low-field magnetic susceptibility was measured at room temperature in the laboratory with a Kappabridge KLY2 ${ }^{\mathrm{TM}}$ (AGICO Inc., Brno, Czech Republic) operating at a frequency of $920 \mathrm{~Hz}$ with a magnetic field intensity of $300 \mathrm{~A} \mathrm{~m}^{-1}$. The sensitivity of this apparatus is about $4 \times 10^{-8} \mathrm{SI}$. A mass of about $5-15 \mathrm{~g}$ of bulk soil sample, crushed into powder to prevent anisotropic effect and without any other particular treatment, was packed into $8 \mathrm{~cm}^{3}$ plastic cubes. Measurements were repeated two to three times and, for half of the samples, two aliquots of the same sample were measured. Obtained uncertainties range from $1 \%$ to $19 \%$.

Effective radium-226 concentration $\mathrm{EC}_{\mathrm{Ra}}$ was measured by radon accumulation experiments in air-tight containers (Stoulos et al., 2003; Girault et al., 2011). A mass $m$ of about $100-200 \mathrm{~g}$ of soil, without any treatment, was inserted in glass bottles, with volumes varying from $260 \mathrm{ml}$ to $400 \mathrm{ml}$ and closed by pre-perforated natural rubber stoppers. The air tightness was systematically checked by depressurization. Radon-222 concentration $C_{\mathrm{Rn}}$ was measured after an accumulation time $t$ varying from 3 to 20 days. The value of $\mathrm{EC}_{\mathrm{Ra}}$, expressed in $\mathrm{Bq} \mathrm{kg}^{-1}$, was then obtained using:

$\mathrm{EC}_{\mathrm{Ra}}=\frac{V_{\mathrm{a}}}{m} \frac{C_{\mathrm{Rn}}}{1-e^{-\lambda t}}$,

where $V_{\mathrm{a}}$ is the total free air volume in the container, $m$ the mass of the sample $(\mathrm{kg})$, and $\lambda$ the radon decay constant $\left(2.1 \times 10^{-6} \mathrm{~s}^{-1}\right)$. In our case, radon concentration was measured by sampling the gas into a previously evacuated scintillation flask, measured after $3.5 \mathrm{~h}$ in a CALEN ${ }^{\mathrm{TM}}$ photomultiplier (Algade, France). The radon concentration was then obtained from the counting rate. The final value of $\mathrm{EC}_{\mathrm{Ra}}$ was obtained by averaging three to four accumulation experiments performed with different accumulation times. The experimental uncertainty, dominated by the statistical uncertainty on the counting rate and a sampling dilution correction, varies from $\pm 10 \%$ for $\mathrm{EC}_{\mathrm{Ra}}$ values of $1 \mathrm{~Bq} \mathrm{~kg}^{-1}$ to 


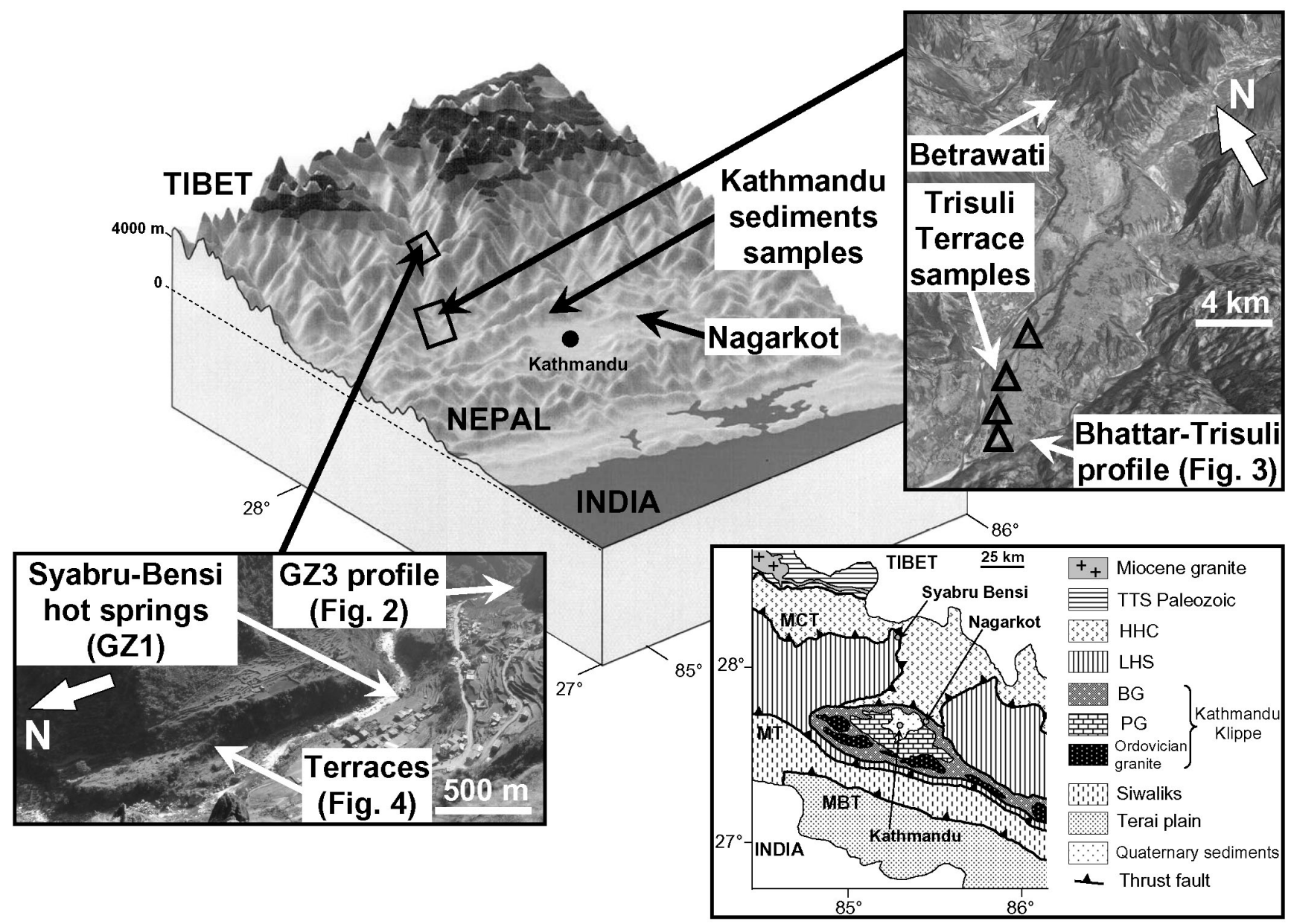

Fig. 1. Location of the sampling sites: the GZ3 profile, the main hot spring site (GZ1) and the three imbricated river terraces in SyabruBensi (in the left picture), the Bhattar-Trisuli profile, the Trisuli Terrace samples (triangles) and Betrawati location (in the right satellite image), the Nagarkot site and the Kathmandu Valley sampling site (in the bloc transect). In the inset, a simplified geological map of Central Nepal (after Upreti, 1999) is shown (TTS: Tethys Tibetan Sediments; HHC: High Himalayan Complex; LHS: Lesser Himalayan Sequences; BG: Bhimphedi Group; PG: Phulchauki Group; MCT: Main Central Thrust; MT: Mahabharat Thrust; MBT: Main Boundary Thrust). The block transect of Central Nepal is a courtesy of Laurent Bollinger; the Trisuli Terrace picture is a GoogleEarth ${ }^{\mathrm{TM}}$ satellite image taken on 10 January 2010.

within $\pm 3 \%$ for $\mathrm{EC}_{\mathrm{Ra}}$ values larger than $10 \mathrm{~Bq} \mathrm{~kg}^{-1}$. For our soil samples, obtained uncertainties range from within $\pm 1 \%$ to within $\pm 13 \%$. When comparing with data sets obtained independently, an additional absolute systematic uncertainty of $\pm 5 \%$, common to all our measurements, is to be combined, so that the total uncertainty squared is the sum of the punctual and absolute uncertainties squared.

\section{Sample sets}

The first set of 34 soil samples was obtained about $500 \mathrm{~m}$ south of the Syabru-Bensi main hot springs in Central Nepal (Fig. 1; Perrier et al., 2009), along a transect (GZ3 profile in Fig. 1) where high fluxes of carbon dioxide and radon had been measured (Girault et al., 2009). This transect (Figs. 1 and 2) was located at an altitude of $1410 \mathrm{~m}$ a.s.l. at the bottom of a debris slope in schists of low metamorphic grade of Lesser Himalayan Sequences (see inset in Fig. 1). One sample was taken every meter during the dry winter season. The samples appeared rich in sand and muscovite. For comparison, 9 black soils rich in organic matter were also collected near the Syabru-Bensi main hot springs (GZ1, Fig. 1). These samples were also rich in sulphur and sulphates due to the release of hydrogen sulphide associated with carbon dioxide. In each of these two locations, GZ1 and GZ3, one soil was also sampled away from the degassing sites, typically at $30 \mathrm{~m}$ and $40 \mathrm{~m}$, respectively.

To study possible magnetic enhancement effects, particular attention was given to red soils, rich in ferric oxides, around Trisuli Bazar, north-west of Kathmandu (Girault et 


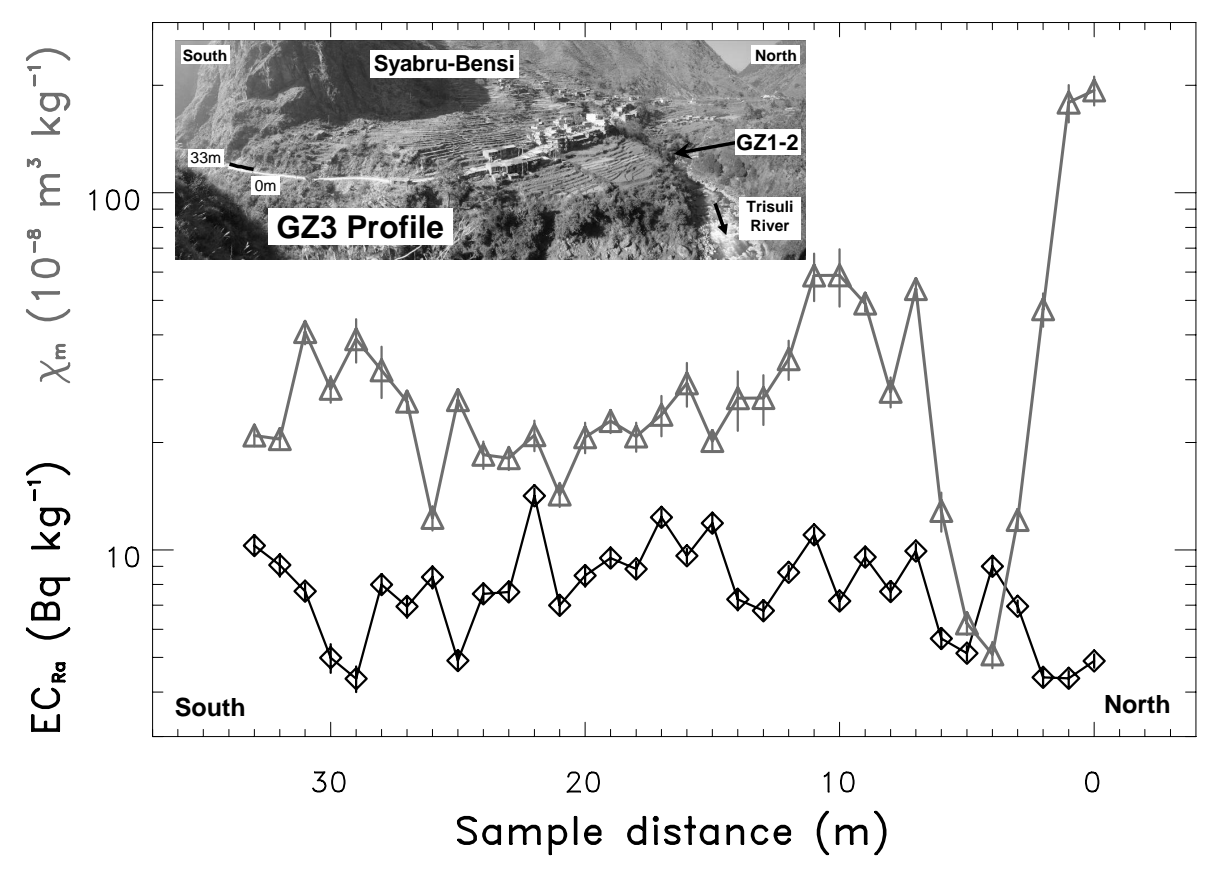

Fig. 2. Transect of $\chi_{\mathrm{m}}$ and $\mathrm{EC}_{\mathrm{Ra}}$ along the gas discharge zone GZ3 south of the main Syabru-Bensi geothermal system, Nepal (Girault et al., 2009). A view of the sampling zone is shown in the inset.

al., 2011). South of the Battar-Trisuli lateritic terrace, located at a mean altitude of $600 \mathrm{~m}$ a.s.l., one scarp was sampled vertically (Bhattar-Trisuli Profile in Fig. 1), with two parallel profiles, separated by $50 \mathrm{~cm}$, of 6 samples from C-horizon, B-horizon to red topsoils (Fig. 3). Four other red residual soils were sampled at other locations of the same terrace (Trisuli Terrace samples in Fig. 1), as well as other locations north of Trisuli Bazar (one sample in Betrawati, in Fig. 1) and north-east of Kathmandu (10 samples in Nagarkot, in Fig. 1).

Additional soil samples were collected in Syabru-Bensi, away from any gas discharge zones, free of red soils or sulphur deposits, on three different imbricated river terraces $\mathrm{T} 1$, T2, T3 at altitudes of $1457 \mathrm{~m}, 1425 \mathrm{~m}$, and $1413 \mathrm{~m}$ a.s.l., respectively (Figs. 1 and 4). Four samples, separated by about $25 \mathrm{~m}$ for $\mathrm{T} 1,2 \mathrm{~m}$ for $\mathrm{T} 2$ and $3 \mathrm{~m}$ for $\mathrm{T} 3$, were taken from each terrace. Soils from terrace T1 were dark, rich in organic matter. The soils from terrace T2 were grey and rich in muscovite, rather similar to GZ3 although in the context of terrace deposits instead of slope debris. The soils from terrace $\mathrm{T} 3$ were more sandy soils. $\mathrm{T} 1$ was the oldest terrace, while the T3 terrace was the youngest. These terraces are not dated precisely but, in the Sub-Himalaya, river incision is particularly rapid, with typical incision rates reaching 10$15 \mathrm{~mm} \mathrm{yr}^{-1}$ (Lavé and Avouac, 2001). Using such rates, the $\mathrm{T} 1, \mathrm{~T} 2$ and $\mathrm{T} 3$ terraces may be dated at $3.8-5.7 \mathrm{ka}, 1.7-2.5 \mathrm{ka}$ and $0.9-1.3 \mathrm{ka}$, respectively.

Finally, 48 soil samples were taken from four similar scarps in the north-western part of the Kathmandu Valley (Fig. 1). These four scarps from the Gokarna Terrace (e.g. Sakai et al., 2008) are characterized by coarse to fine sand and orange, brown and black clays, and were separated from $30 \mathrm{~cm}$ to $2.5 \mathrm{~km}$ (Girault et al., 2011). Twelve samples were collected on each vertical profile, and each sample had its counterpart in the same layer in the three other profiles.

\section{Results}

The results for different sampling sites are shown in Figs. 2 to 4 . An overview of $\chi_{\mathrm{m}}$ versus $\mathrm{EC}_{\mathrm{Ra}}$ for all sites is shown in Fig. 5.

Both $\chi_{\mathrm{m}}$ and $\mathrm{EC}_{\mathrm{Ra}}$ were rather homogeneous along the GZ3 profile (Fig. 2), with average values of $(36.7 \pm 6.9) \times 10^{-8} \mathrm{~m}^{3} \mathrm{~kg}^{-1}$ and $7.9 \pm 0.4 \mathrm{~Bq} \mathrm{~kg}^{-1}$ for $\chi_{\mathrm{m}}$ and $\mathrm{EC}_{\mathrm{Ra}}$, respectively. Both these values and their standard deviations, $40.4 \times 10^{-8} \mathrm{~m}^{3} \mathrm{~kg}^{-1}$ and $2.4 \mathrm{~Bq} \mathrm{~kg}^{-1}$, respectively, are typically observed values in soils from Nepal (Gautam et al., 2009; Girault et al., 2011) and this set, thus, can be considered as a standard baseline. While smooth spatial variations were observed in both variables along the profile, no clear pattern emerged in the $\chi_{\mathrm{m}}$ versus $\mathrm{EC}_{\mathrm{Ra}}$ correlation plot (Fig. 5).

The two vertical profiles at the Bhattar-Trisuli scarp (Fig. 3) provided a different situation. While conspicuous vertical variations were observed, both in $\chi_{\mathrm{m}}$ and $\mathrm{EC}_{\mathrm{Ra}}$, the two vertical profiles were similar, thus indicating that lateral variations were negligible compared with vertical variations. A clear magnetic enhancement effect was observed, with $\chi_{\mathrm{m}}$ increasing from low values from 

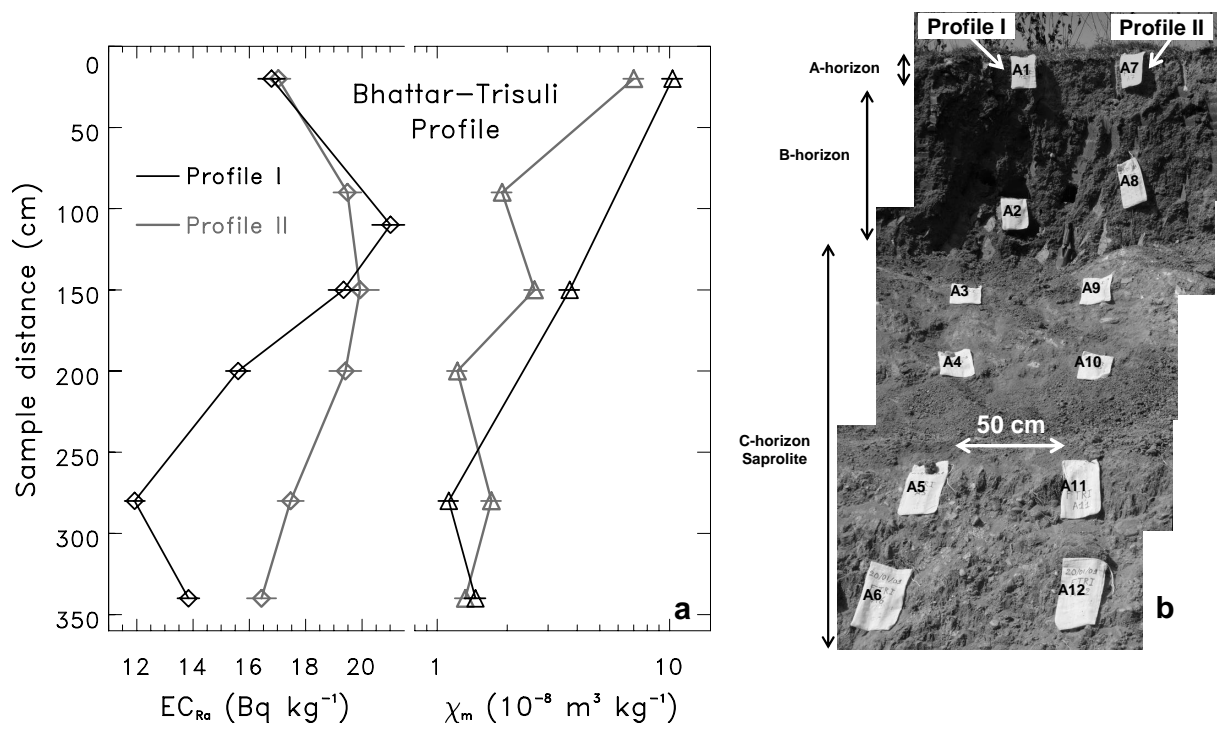

Fig. 3. (a) Vertical profiles of $\chi_{m}$ and $\mathrm{EC}_{\mathrm{Ra}}$ along a scarp of the Bhattar-Trisuli terrace, Nepal (Girault et al., 2011). A view of the scarp is shown in (b).
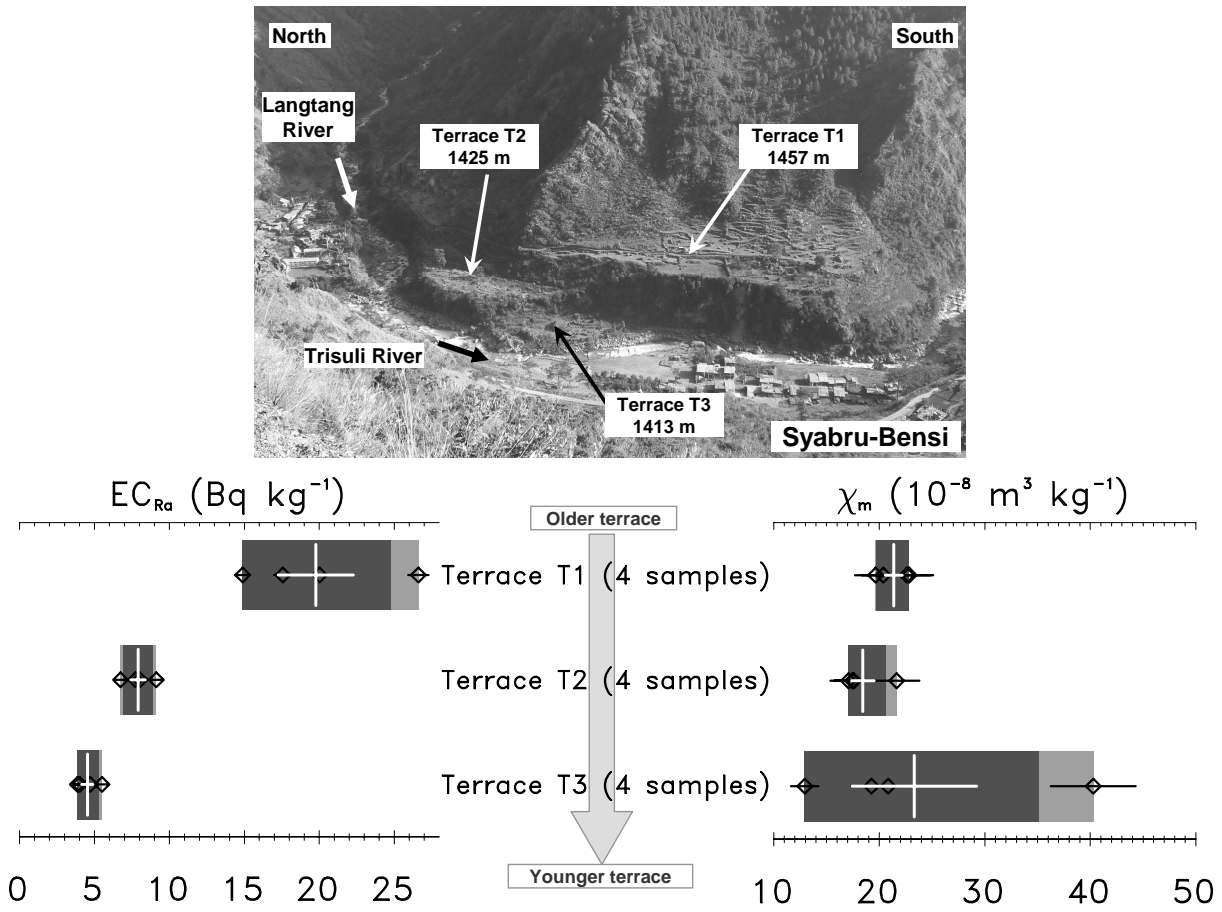

Fig. 4. Results of $\chi_{m}$ and $\mathrm{EC}_{\mathrm{Ra}}$ on three imbricated river terraces, Syabru-Bensi, Nepal. A view of the terraces on the left bank of the Trisuli River in Syabru-Bensi is shown above the graphs.

$1 \times 10^{-8}$ to $2 \times 10^{-8} \mathrm{~m}^{3} \mathrm{~kg}^{-1}$ for the C-horizon, to from $3 \times 10^{-8}$ to $4 \times 10^{-8} \mathrm{~m}^{3} \mathrm{~kg}^{-1}$ for the B-horizon and from $7 \times 10^{-8}$ to $10 \times 10^{-8} \mathrm{~m}^{3} \mathrm{~kg}^{-1}$ for the topsoil. Note, however, that the increase of $\chi_{\mathrm{m}}$ by about a factor of 10 is similar to the range of variation in Fig. 2. While the average value $17.4 \pm 0.7 \mathrm{~Bq} \mathrm{~kg}^{-1}$ of $\mathrm{EC}_{\mathrm{Ra}}$ in this set was rather high
(Girault et al., 2011), a small but significant spatial variation can be seen in Fig. 3a, with a local maximum at the interface between the B-horizon and the C-horizon at about $100 \mathrm{~cm}$ depth. In Fig. 5, this data set is characterized by a vertical inverted $\mathrm{C}$ shape with no overlap with the domain of the data points of the GZ3 profile. 


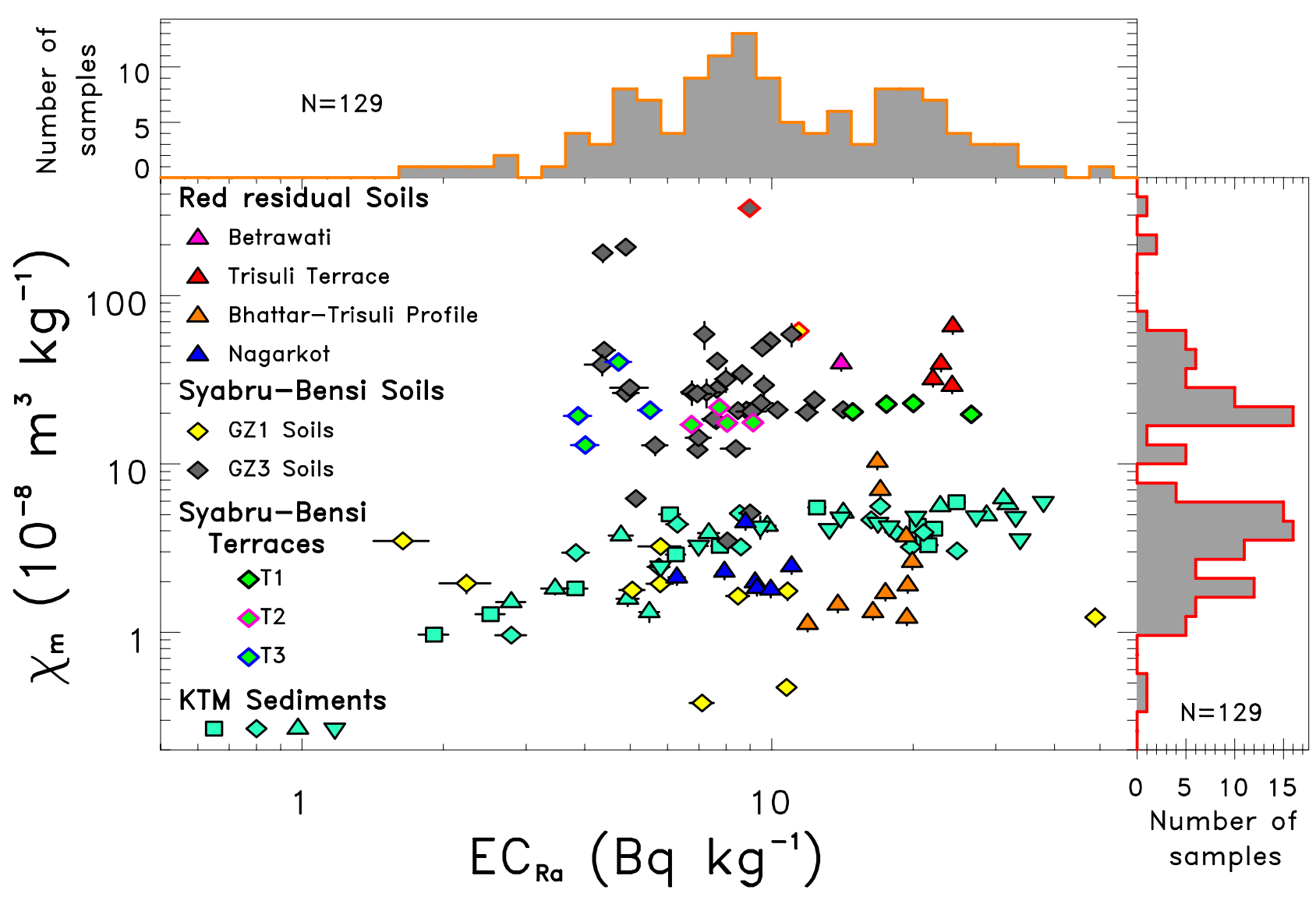

Fig. 5. Summary of the results of $\chi_{m}$ versus $E_{R}$. Soils from the Syabru-Bensi geothermal system are shown as diamonds, with a different border colour for the three imbricated river terraces T1-3. Red soils from various locations north-west and north-east of Kathmandu, Nepal, are shown as triangles. The four symbols for Kathmandu (KTM) sediments correspond to the four sampling locations of the same stratigraphical levels. Black and grey diamonds with red borders correspond to soils sampled $30 \mathrm{~m}$ and $40 \mathrm{~m}$ away from GZ1 and GZ3, respectively.

The results of the soil samples from the imbricated terraces $\mathrm{T} 1, \mathrm{~T} 2$ and $\mathrm{T} 3$ are presented in Fig. 4. The obtained values of $\chi_{\mathrm{m}}$ varied between $(12.9 \pm 1.3) \times 10^{-8} \mathrm{~m}^{3} \mathrm{~kg}^{-1}$ and $(40.3 \pm 4.0) \times 10^{-8} \mathrm{~m}^{3} \mathrm{~kg}^{-1}$, thus, significantly larger than the topsoil values observed in the vertical profiles from other locations in Nepal (Fig. 3), but similar to the values obtained for the nearby GZ3 profile (Fig. 2). One interesting feature in Fig. 4, although statistics remain low (4 samples for each terrace), is that the values of $\chi_{\mathrm{m}}$ for $\mathrm{T} 1$ and $\mathrm{T} 2$ did not overlap significantly, while the values for $\mathrm{T} 3$ overlapped both the domains of values for $\mathrm{T} 1$ and $\mathrm{T} 2$. By contrast, the values of $\mathrm{EC}_{\mathrm{Ra}}$ showed a large range of variations from $3.9 \pm 0.3 \mathrm{~Bq} \mathrm{~kg}^{-1}$ to $26.6 \pm 0.7 \mathrm{~Bq} \mathrm{~kg}^{-1}$, not insignificant compared with the range of variations ( 0.4 to $43 \mathrm{~Bq} \mathrm{~kg}^{-1}$ ) observed over smaller spatial scales in Kathmandu Valley (Girault et al., 2011). In addition, each terrace was characterized by non-overlapping values of $\mathrm{EC}_{\mathrm{Ra}}$, with average values of $20 \pm 3 \mathrm{~Bq} \mathrm{~kg}^{-1}, 7.9 \pm 0.5 \mathrm{~Bq} \mathrm{~kg}^{-1}$, and $4.5 \pm 0.4 \mathrm{~Bq} \mathrm{~kg}^{-1}$, respectively, for $\mathrm{T} 1, \mathrm{~T} 2$ and $\mathrm{T} 3$. Thus, $\mathrm{EC}_{\mathrm{Ra}}$ appeared to increase regularly from the younger to the older terrace. In the correlation plot (Fig. 5), this data set appears as a horizontal set of points, non-overlapping with the data set of Bhattar-Trisuli profiles but with the data set of GZ3.

The three data sets described so far (Figs. 2 to 4), thus, were scattered in different domains of $\chi_{\mathrm{m}}$ versus $E C_{\mathrm{Ra}}$ in Fig. 5. This remains true when further data are now considered. Soil samples collected at the main geothermal system of Syabru-Bensi (GZ1), were characterized by a large range of $\mathrm{EC}_{\mathrm{Ra}}$, from $1.6 \pm 0.2 \mathrm{~Bq} \mathrm{~kg}^{-1}$ to $49 \pm 0.4 \mathrm{~Bq} \mathrm{~kg}^{-1}$, associated with significantly low values of $\chi_{\mathrm{m}}$, from $(0.38 \pm 0.02) \times 10^{-8} \mathrm{~m}^{3} \mathrm{~kg}^{-1}$ to $(3.5 \pm 0.2) \times 10^{-8} \mathrm{~m}^{3} \mathrm{~kg}^{-1}$. Thus, this data set does not agree with the GZ3 data. By contrast, the reference soil sample in GZ1 (bordered in red in Fig. 5), taken $30 \mathrm{~m}$ away from the gas discharge, falls in the cluster of GZ3 data.

Other red soils, superficially similar to the topsoils of the Bhattar-Trisuli profiles, showed contrasting behaviours. The four red soils of the Trisuli Terrace, above the site of the Bhattar-Trisuli profiles (Fig. 1), 
are characterized by roughly similar values of $\mathrm{EC}_{\mathrm{Ra}}$, with an average of $23.4 \pm 0.5 \mathrm{~Bq} \mathrm{~kg}^{-1}$ and much higher values of $\chi_{\mathrm{m}}$, varying from $(29.1 \pm 2.9) \times 10^{-8} \mathrm{~m}^{3} \mathrm{~kg}^{-1}$ to $(65.6 \pm 6.6) \times 10^{-8} \mathrm{~m}^{3} \mathrm{~kg}^{-1}$ (Fig. 5). The red soil from Betrawati (Fig. 1) showed a slightly smaller value of $\chi_{\mathrm{m}}$ of $(39.6 \pm 4.0) \times 10^{-8} \mathrm{~m}^{3} \mathrm{~kg}^{-1}$, but a significantly smaller value of $\mathrm{EC}_{\mathrm{Ra}}\left(14.1 \pm 0.4 \mathrm{~Bq} \mathrm{~kg}^{-1}\right)$. The 6 red soil samples from the Nagarkot area (Fig. 1), by contrast, showed smaller values of both $\chi_{\mathrm{m}}$ and $\mathrm{EC}_{\mathrm{Ra}}$, thus falling in the domain of the GZ1 data set (Fig. 5). Thus, the various sets of red soils are distinguished easily when looking at $\chi_{\mathrm{m}}$ versus $\mathrm{EC}_{\mathrm{Ra}}$.

Furthermore, the four sets of sediment profiles collected in the Kathmandu Valley (Fig. 1) were characterized by a moderate range of variation of $\chi_{\mathrm{m}}$, from $(0.96 \pm 0.05) \times 10^{-8} \mathrm{~m}^{3} \mathrm{~kg}^{-1}$ to $(6.2 \pm 0.1) \times 10^{-8} \mathrm{~m}^{3} \mathrm{~kg}^{-1}$, but by a larger range of variation of $\mathrm{EC}_{\mathrm{Ra}}$, from $1.9 \pm 0.1 \mathrm{~Bq} \mathrm{~kg}^{-1}$ to $37.9 \pm 0.8 \mathrm{~Bq} \mathrm{~kg}^{-1}$ (Fig. 5). This behaviour is consistent among the four profiles, although they are separated by up to $2.5 \mathrm{~km}$. These samples also showed a slight trend from sand layers characterized by low $\mathrm{EC}_{\mathrm{Ra}}$ and $\chi_{\mathrm{m}}$ values to brown clay layers characterized by higher $\mathrm{EC}_{\mathrm{Ra}}$ and $\chi_{\mathrm{m}}$ values (Fig. 5). Those results intersect the domains of GZ1 samples and red residual soils from Nagarkot and Bhattar-Trisuli profile.

The distribution of all $\chi_{\mathrm{m}}$ values shows two clusters: one around $25 \times 10^{-8} \mathrm{~m}^{3} \mathrm{~kg}^{-1}$ with samples from the Trisuli Terrace and upper Trisuli valley, and one around $3 \times 10^{-8} \mathrm{~m}^{3} \mathrm{~kg}^{-1}$ with all samples south of Trisuli Terrace, with the exception of the GZ1 samples. These two clusters might be due to different geological input, suggesting some sensitivity of $\chi_{\mathrm{m}}$ to the parent material.

\section{Discussion and conclusion}

In this study, we have obtained values of $\chi_{\mathrm{m}}$ and $\mathrm{EC}_{\mathrm{Ra}}$ from 129 soil samples. Significant and consistent behaviours have emerged, with variations much larger than the experimental uncertainties. This suggests that the potential of these two physical parameters, which are easy and cost-effective to measure without any disruption of the sample, deserve further exploration for soil physics. Indeed, while some soil samples sets are difficult to distinguish on the basis of one of these parameters only, definite discrimination may be possible when their combination is considered. In particular, magnetic enhancement, which we would now define as a $\chi_{\mathrm{m}}$ increase occurring at roughly constant $\mathrm{EC}_{\mathrm{Ra}}$, can be distinguished from parent material heterogeneity or pollutant effects associated with widely different values of both $\chi_{\mathrm{m}}$ and $\mathrm{EC}_{\mathrm{Ra}}$. By contrast, an increase of $\mathrm{EC}_{\mathrm{Ra}}$ at constant $\chi_{\mathrm{m}}$ would indicate, for example, an enrichment in organic matter at a constant average mineralogy, possibly associated with a change in deposition age.

The argument is not only qualitative, but quantitative. First, the two properties $\mathrm{EC}_{\mathrm{Ra}}$ and $\chi_{\mathrm{m}}$ are generally poorly correlated, in particular for GZ1 and GZ3 soil samples, for which the correlation coefficients are $0.44 \pm 0.02$ and $0.58 \pm 0.03$, respectively. Thus, combining both parameters leads to an increase of information compared with their separate measurements. In addition, relevant interest in the measurement of both these parameters lies in their respective different behaviour, which can also be demonstrated by using, for some data sets, the coefficient of variation (expressed in per cent). For example, the Trisuli Terrace red residual soil samples (Fig. 5) show a low ratio of $4.6 \%$ for $\mathrm{EC}_{\mathrm{Ra}}$ and a larger value of $40 \%$ for $\chi_{\mathrm{m}}$. Conversely, for other data sets such as the Syabru-Bensi Terraces soil samples (Fig. 5), we obtain a larger ratio for $\mathrm{EC}_{\mathrm{Ra}}(68 \%)$ than for $\chi_{\mathrm{m}}(32 \%)$. Therefore, $\mathrm{EC}_{\mathrm{Ra}}$ and $\chi_{\mathrm{m}}$ definitely appear to be non-redundant physical properties of soils. Finally, the relative patterns of $\mathrm{EC}_{\mathrm{Ra}}$ and $\chi_{\mathrm{m}}$ can be used to discriminate soil groups. For example, considering GZ3 soils on one hand, and Trisuli Terrace samples and Bhattar-Trisuli profile soils together on the other hand, in Fig. 5, separation between the two groups is difficult on the basis of $\mathrm{EC}_{\mathrm{Ra}}$ or $\chi_{\mathrm{m}}$ only. When, however, a separation line is drawn in $\chi_{\mathrm{m}}$ versus $\mathrm{EC}_{\mathrm{Ra}}$ parameter space, the two sample sets are now clearly isolated, with relative contamination of the order of $\leq 1 \%$ at the $90 \%$ confidence level, a conclusion that can now be subjected to further independent statistical tests.

Consistent behaviours were observed with samples separated by large distances, which suggests that the pattern is controlled by stratigraphical position and regional evolution rather than site specific contamination or infiltration effects. More systematic campaigns are necessary to establish such behaviours and associated trajectories in the $\chi_{\mathrm{m}}$ versus $\mathrm{EC}_{\mathrm{Ra}}$ parameter space. To observe such behaviours, it is important to study coherent soil samples with erosion or deposition conditions varying while the overall context is sufficiently constant. Consequently, our initial observations would benefit from more complete investigations and dedicated experiments, in order to obtain for example the nature of magnetic phases and the Fe-oxides characteristics (Jordanova et al., 2010).

While tentative at this stage, physical explanations for the observed behaviours can be proposed. Although increase of $\chi_{\mathrm{m}}$ in topsoils could be dominated by short time-scale alteration and oxide minerals content, $\mathrm{EC}_{\mathrm{Ra}}$ heterogeneities would indicate, first of all, the heterogeneity of residual clay from parent material and cumulated leaching. Also, the increase of $\mathrm{EC}_{\mathrm{Ra}}$ with soil age, for other conditions roughly constant, might be accounted for by the increasing amount of organic matter, which is a particularly interesting factor for radium removal from groundwater. To develop a better understanding of $\chi_{\mathrm{m}}$ versus $\mathrm{EC}_{\mathrm{Ra}}$ patterns, controlled experiments in the laboratory can be of great interest, in particular to investigate how these patterns can be modified by the presence of contaminants. 


\section{Supplementary material related to this article is available online at: \\ http://www.nat-hazards-earth-syst-sci.net/11/2285/2011/ nhess-11-2285-2011-supplement.pdf.}

Acknowledgements. The authors thank Soma Nath Sapkota (Department of Mines and Geology, Kathmandu, Nepal) and Gauthier Hulot (Institut de Physique du Globe de Paris, France) for continuous support over the years. Hélène Bouquerel is thanked for technical assistance and France Lagroix for her valuable comments about magnetic susceptibility in soils. The original manuscript has been improved thanks to two anonymous reviewers. This paper is IPGP contribution number 3209.

Edited by: R. Crockett

Reviewed by: J.-C. Sabroux and another anonymous referee

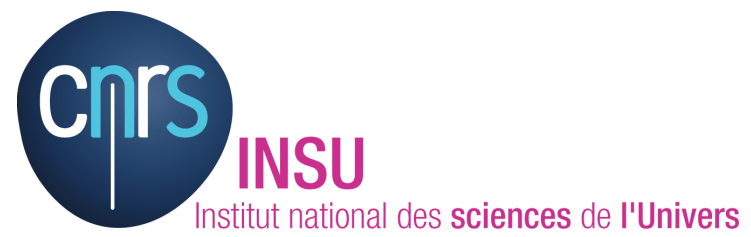

The publication of this article is financed by CNRS-INSU.

\section{References}

Adler, P. M. and Perrier, F.: Radon emanation in partially saturated porous media, Transport in Porous Media, 78(2), 149-159, 2009.

Ames, L. L., McGarrah, J. E., Walker, B. A., and Salter, P. F.: Uranium and radium sorption on amorphous ferric oxyhydroxide, Chem. Geol., 40, 135-148, 1983.

Banwart, S.: Save our soils, Nature, 474, 151-152, 2011.

Blundell, A., Dearing, J. A., Boyle, J. F., and Hannam, J. A.: Controlling factors for the spatial variability of soil magnetic susceptibility across England and Wales, Earth-Sci. Rev., 95, 158-188, 2009.

Botset, H. G. and Weaver, P.: Radon content of soil gas, Physics, 2, 376-385, 1932.

Breitner, D., Arvela, H., Hellmuth, K.-H., and Renvall, T.: Effect of moisture content on emanation at different grain size fractions A pilot study on granitic esker sand sample, J. Environ. Radioactiv., 101, 1002-1006, 2010.

de Jong, E., Nestor, P. A., and Pennock, D. J.: The use of magnetic susceptibility to measure long-term soil redistribution, Catena, 32, 23-36, 1998.

D’Emilio, M., Caggiano, R., Coppola, R., Macchiato, M., and Ragosta, M.: Magnetic susceptibility measurements as proxy method to monitor soil pollution: the case study of S. Nicola di Melfi, Environ. Monit. Assess., 169, 619-630, 2010.

Dearing, J. A., Hay, K. L., Baban, S. M. J., Huddleston, A. S., Wellington, E. M. H., and Loveland, P. J.: Magnetic susceptibility of soil: an evaluation of conflicting theories using a national data set, Geophys. J. Int., 127, 728-734, 1996.
Evans, M. and Heller, F.: Environmental magnetism. Principles and applications of enviromagnetics, Academic Press, Elsevier Science (USA), 2003.

Flexser, S., Wollenberg, H. A., and Smith, A. R.: Distribution of radon sources and effects on radon emanation in granitic soil at Ben Lomond, California, Environ. Geol., 22, 162-177, 1993.

Gautam, P., Sakai, T., Paudayal, K. N., Bhandari, S., Gyawali, B. R., Gautam, C. M., and Rijal, M. L.: Magnetism and granulometry of Pleistocene sediments of Dhapasi section, Kathmandu (Nepal): implications for depositional age and paleoenvironment, Bulletin of the Department of Geology, Tribhuvan University, Kathmandu, Nepal, 12, 17-28, 2009.

Girault, F., Koirala, B. P., Perrier, F., Richon, P., and Rajaure, S.: Persistence of radon-222 flux during monsoon at a geothermal zone in Nepal, J. Environ. Radioactiv., 100, 955-964, 2009.

Girault, F., Gajurel, A. P., Perrier, F., Upreti, B. N., and Richon, P.: Radon emanation of heterogeneous basin deposits in Kathmandu Valley, Nepal, J. Asian Earth Sci., 40, 595-610, 2011.

Greeman, D. J., Rose, A. W., Washington, J. W., Dobos, R. R., and Ciolkosz, E. J.: Geochemistry of radium in soils of the Eastern United States, Appl. Geochem., 14, 365-385, 1999.

Gu, Z. Y., Lal, D., Liu, T. S., Guo, Z. T., Southon, J., and Caffee, M. W. M.: Weathering histories of Chinese loess deposits based on uranium and thorium series radionuclides and cosmogenic ${ }^{10} \mathrm{Be}$, Geochim. Cosmochim. Ac., 61, 5221-5231, 1997.

Hanesch, M. and Scholger, R.: Mapping of heavy metal loadings in soils by means of magnetic susceptibility measurements, Environ. Geol., 42, 857-870, 2002.

Jordanova, D., Jordanova, N., Petrov, P., and Tsacheva, Ts.: Soil development of three Chernozem-like profiles from North Bulgaria revealed by magnetic studies, Catena, 83, 158-169, 2010.

Karimi, R., Ayoubi, S., Jalalian, A., Sheikh-Hosseini, A. R., and Afyuni, M.: Relationship between magnetic susceptibility and heavy metals in urban topsoils in the arid region of Isfahan, central Iran, J. Appl. Geophys., 74, 1-7, 2011.

Lagroix, F. and Banerjee, S. K.: Paleowind directions from the magnetic fabric of loess profiles in central Alaska, Earth Planet. Sci. Lett., 195, 99-112, 2002.

Lavé, J. and Avouac, J. P.: Fluvial incision and tectonic uplift across the Himalayas of central Nepal, J. Geophys. Res., 106(B11), 26561-26591, 2001.

Le Borgne, E.: Susceptibilité magnétique anormale du sol superficiel, Ann. Géophys., 11, 399-419, 1955.

Markkanen, M. and Arvela, H.: Radon emanation from soils, Radiat. Prot. Dosim., 45(1/4), 269-272, 1992.

Mullins, C. E.: Magnetic susceptibility of the soil and its significance in soil science - a review, J. Soil Sci., 28, 223-246, 1977.

Musy, A., and Soutter, M.: Physique du sol (Presses polytechniques et universitaires romandes, Lausanne), 1991 (in French).

Perrier, F., Richon, P., Byrdina, S., France-Lanord, C., Rajaure, S., Koirala, B. P., Shrestha, P. L., Gautam, U. P., Tiwari, D. R., Revil, A., Bollinger, L., Contraires, S., Bureau, S., and Sapkota, S. N.: A direct evidence for high carbon dioxide and radon-222 discharge in Central Nepal, Earth Planet. Sci. Lett., 278, 198-207, 2009.

Sahoo, B. K., Mayya, Y. S., Sapra, B. K., Gaware, J. J., Banerjee, K. S., and Kushwaha, H. S.: Radon exhalation studies in an Indian uranium tailings pile, Radiat. Meas., 45, 237-241, 2010.

Sakai, T., Gajurel, A. P., Tabata, H., Ooi, N., Takagawa, T., 
Kitagawa, H. and Upreti, B. N.: Revised lithostratigraphy of fluvio-lacustrine sediments comprising northern Kathmandu basin in central Nepal, J. Nepal Geol. Soc., 37, 25-44, 2008.

Stoulos, S., Manolopoulou, M., and Papastefanou, C.: Assessment of natural radiation exposure and radon exhalation from building materials in Greece, J. Environ. Radioactiv., 69, 225-240, 2003.
Stoulos, S., Manolopoulou, M., and Papastefanou, C.: Measurement of radon emanation factor from granular samples: effects of additives in cement, Appl. Radiat. Isotopes, 60, 49-54, 2004.

Thompson, R. and Oldfield, F.: Environmental magnetism, Allen \& Unwin, London, 1986.

Upreti, B. N.: An overview of the stratigraphy and tectonics of the Nepal Himalaya, J. Asian Earth Sci., 17, 577-606, 1999. 